\title{
THE DISTANCE OF ATTRACTION OF CDC LIGHT TRAPS TO PHLEBOTOMINE SANDFLIES
}

\author{
R. KILLICK-KENDRICK ${ }^{*}$, T. J. WILKES*, J. ALEXANDER*, R. S. BRAY ${ }^{*}$, \\ J.-A. RIOUX** and M. BAILLY*
}

\begin{abstract}
SUMMARY. The range from which Phlebotomus ariasi Tonnoir, 1921 is attracted to a CDC light trap was studied in the field in France by suspending a CDC trap, without a cage, over one of a line of 7 large suction (LS) traps. The LS trap under the CDC trap caught many more sandflies than the other LS traps and the pattern of the catches showed that $P$. ariasi is attracted to the light of a CDC trap at distances $<2 \mathrm{~m}$. It is concluded that, in studies on the dispersal of marked sandflies, CDC traps would not artificially increase the distance of dispersal and that, in suitable weather, the aerial population of $P$. ariasi is large and constantly moving during the nocturnal period of activity.
\end{abstract}

\section{Distances d'attraction des pièges lumineux CDC vis-à-vis des Phlébotomes.}

RÉSUMÉ. Ia distance à laquelle Phlebotomus ariasi Tonnoir, 1921 peut être attiré par un piège lumineux CDC a été étudiée dans le foyer leishmanien des Cévennes, à Roquedur-le-Bas (Gard). Pour cela, un piège CDC a été suspendu sans cage, au-dessus d'un alignement de 7 grands pièges à succion (LS). Le piège LS disposé sous le piège CDC a capturé beaucoup plus de Phlébotomes que les autres pièges LS. L'échantillonnage des prises a montré que $P$. ariasi est attiré par le piège $\mathrm{CDC}$ à une distance inférieure à $2 \mathrm{~m}$. Deux conclusions sont tirées : les pièges lumineux CDC n'accroissent pas artificiellement les distances de dispersion dans les études portant sur des Phlébotomes marqués; sous réserve de conditions météorologiques convenables et pendant la période d'activité nocturne, la population aérienne de $P$. ariasi est à la fois importante et constamment mobile.

In a mark-release- recapture study of the dispersal of Phlebotomus ariasi Tonnoir, 1921 in the Cévennes, southern France, we used CDC miniature light traps* as one method of recapturing marked flies and fcund that the flies commonly moved up to $1 \mathrm{~km}$ or, rarely, $2 \mathrm{~km}$ from the point of release (Killick-Kendrick et al., 1984). This sandfly is a proven vector of Leishmania infantum Nicolle, 1908 (see review by

* Department of Pure and Applied Biology, Imperial College, London, SW7 2AZ, England.

* Laboratoire d'Écologie médicale et Pathologie parasitaire, Faculté de Médecine, F 34000 Montpellier.

I. External Scientific Staff, Medical Research Council, London.

* Hausherr's Machine Works, Old Freehold Rd., Toms River, N. J. 08753, USA.

Accepté le 7 septembre I 984 . 
Killick-Kendrick and Rioux, 1981) and it was concluded that movement of the fly was a factor in the spread of visceral leishmaniasis from one place to another in the Cévennes focus. There was, however, a possibility that the distances of dispersal had been artificially increased by the use of the CDC traps the lights of which may have attracted the sandflies from considerable distances. In the summer of 1983, therefore, we carried out field experiments to find out from what distance $P$. ariasi is attracted to CDC traps.

\section{Materials and Methods}

Three experiments were carried out in a valley in the commune of Roquedur, Gard, France, which is described by Rioux et al. (1979). One experiment was done on the night of 27-28 July, 1983 and two on the following night.

Large suction (LS) traps were made with 9 in $(23 \mathrm{~cm})$ Standard model Ventaxia* fans mounted horizontally on a wooden frame with a cross section of $37 \times$ $37 \mathrm{~cm}$ and a height of $58 \mathrm{~cm}$. A copper gauze cone $25 \mathrm{~cm}$ in diameter at the mouth and $30 \mathrm{~cm}$ in length was fitted to the exhaust side of the fan. A brass tube $8 \mathrm{~cm}$ long by $8.5 \mathrm{~cm}$ in diameter, forming the bottom of the cone, rested inside a nylon gauze cage suspended by tapes in a wood and wire frame $(24 \times 24 \times 24 \mathrm{~cm})$. Insects passing over the fans were sucked in and blown through the cone into the cage (Snow, 1975). A CDC light trap without a collecting cage was suspended over one of these traps so that the light bulb of the CDC trap was centrally placed $23 \mathrm{~cm}$ from the top of the fan of the LS trap. The light was a $6 \mathrm{~V} 60 \mathrm{~mA}$ spherical bulb giving 1 nominal lumen at $6 \mathrm{~V}(0.08 \mathrm{~cd})$; the trap was powered by 4 rechargeable $1.5 \mathrm{~V}$ batteries which were fully charged at the beginning of each experiment.

Seven LS traps, powered by a generator, were set up on a hillside in a line, $2 \mathrm{~m}$ apart, according to a prevailing katabatic wind. Three LS traps were upwind and 3 downwind of the LS trap with the suspended CDC trap above it. The LS traps were run at the lowest of the three speeds available on the control boxes. The mean speed $( \pm \mathrm{SD})$ of the 7 traps was $726 \pm 33.1$ r.p.m.

In experiment 1, the traps were run for 50 mins ; in experiments 2 and 3 , they were run for 60 mins. The average wind speed of the previous 10 secs and ambient temperatures were recorded at 5 minute intervals. Wind direction was recorded with an ultrasensitive wind vane which responded to winds of $<0.1 \mathrm{~m} / \mathrm{sec}$. It was connected to a "Rustrak 280" single channel recorder modified to include an interface with the opto-recorder of the sensor**. Readings were recorded every $2 \mathrm{sec}$ on a chart moving at $25.5 \mathrm{~cm} / \mathrm{h}$.

All sandflies caught (expt 1) or samples of one third of the catch (expts 2 and 3 ) were identified as $P$. ariasi by the examination of the external genitalia of males or the spermathecae of females. Of many thousands of identified sandflies caught in LS

* Ventaxia Ltd., Fleming Way, Crawley, West Sussex RHIo 2NN, England.

** Didcot Instrument Co. Ltd., Station Rd., Abingdon, Oxfordshire, OXI4 3LD, England. 
traps on the same study site in other work, over $99 \%$ were $P$. ariasi; the remainder were rare specimens of $P$. perniciosus Newstead, 1911 or P. mascittii Grassi, 1908. It is therefore assumed that the unidentified flies in the present work were $P$. ariasi.

\section{Results}

The numbers of female sandflies caught in each LS trap in three experiments are shown in table $I$. With the results of experiment 1 (which was run for only $50 \mathrm{~min}$ ) corrected to express the catch as females per trap hour, the following comparisons can be made. The mean number ( $\pm \mathrm{SE}$ ) of females caught in the LS trap with a CDC trap suspended above it was $24.9 \pm 8.0$ per trap hour. That of the LS traps without a C.DC was $8.5 \pm 0.75$. This last figure is not significantly different from the mean number $(8.3 \pm 0.49)$ of females of the aerial population caught per trap hour in the same LS traps without bait animals (or CDC trap) in six control experiments run in the same place in unpublished observations on the host finding behaviour of $P$. ariasi. The mean numbers ( $\pm \mathrm{SE}$ ) of female flies caught in LS traps downwind from the CDC trap (5,6 and 7) compared to those upwind $(1,2$ and 3 ) were not significantly different $(9.00 \pm 1.22$ and $8.04 \pm 0.94$ per trap hour $; p=>0.05)$.

In addition to the total of 220 female sandflies caught in the three experiments, 45 male flies were captured. The numbers of males per trap varied from $0-6$ and the ratio of males to females was $1: 5$.

TABLE I. - Showing numbers of female $P$. ariasi caught in each of a series of large suction traps over one of which (No 4) a CDC light trap was suspended.

\begin{tabular}{|c|c|c|c|c|}
\hline \multirow{2}{*}{ Nos of LS traps } & \multicolumn{3}{|c|}{ Numbers (and \%) of +9 per trap } & \multirow{2}{*}{$\begin{array}{c}\text { Totals } \\
\text { (and \%) of } \\
\text { ofo per trap }\end{array}$} \\
\hline & Expt 1 & Expt 2 & Expt 3 & \\
\hline 1 & $4(9.8)$ & $10(8.9)$ & $9(13.4)$ & $23(10.5)$ \\
\hline 2 & $5(12.2)$ & $10(8.9)$ & $7(10.5)$ & $22(10.0)$ \\
\hline 3 & $3(7.3)$ & $12(10.7)$ & $10(14.9)$ & $25(11.4)$ \\
\hline $4+\mathrm{CDC}$ & $14(34.1)$ & $41(36.6)$ & $17(25.4)$ & $72(32.7)$ \\
\hline 5 & $4(9.8)$ & $17(15.2)$ & $8(11.9)$ & $29(13.2)$ \\
\hline 6 & $6(14.6)$ & $12(10.7)$ & $8(11.9)$ & $26(11.8)$ \\
\hline 7 & $5(12.2)$ & $10(8.9)$ & $8(11.9)$ & $23(10.5)$ \\
\hline Totals & $41(100.0)$ & $112(100.0)$ & $67(100.0)$ & $220(100.0)$ \\
\hline Time of experiment & $23.43-00.33 \mathrm{~h}$ & $22.43-22.43 \mathrm{~h}$ & $00.10-01.10 \mathrm{~h}$ & \\
\hline Mean ${ }^{\circ} \mathrm{C} \pm \mathrm{SE}:$ & $21.8 \pm 0.09$ & $22.8 \pm 0.21$ & $21.1 \pm 0.12$ & \\
\hline Mean wind speed $(\mathrm{m} / \mathrm{sec}) \pm \mathrm{SE}$ & $: 0.13 \pm 0.04$ & $0.25 \pm 0.04$ & $0.16 \pm 0.06$ & \\
\hline $\begin{array}{l}\text { Proportion of period } \\
\text { with wind down line : }\end{array}$ & $100 \%$ & $66 \%$ & $56 \%$ & \\
\hline
\end{tabular}




\section{Discussion}

The wind speeds throughout all three experiments were well below levels which adversely affect the activity of $P$. ariasi. The comparatively high total catch in experiment 2 was probably due partly to the temperature, which was higher than during the other two experiments, but mostly to the time of experiment 2 which was the only one of the three done wholly during the peak period of activity of P. ariasi (21.00-24.00 hrs; Rioux et al., 1969).

The high numbers of sandflies caught in LS trap 4 are explained by the attraction of flies to the suspended light trap. In our unpublished work on host finding behaviour done in the same place as this work, it was found that, like mosquitoes, $P$. ariasi females move against winds of suitable speeds in search of a host and it is known, therefore, that the general direction of travel of the flies caught in the experiments described here was from LS trap 7 upwind to LS trap 1. Had the flies been homing in against the wind towards the CDC trap from distances $>2 \mathrm{~m}$, larger numbers would have been caught in the downwind than the upwind traps. The absence of a gradient of numbers of flies in the LS traps downwind from trap 4, and the lack of difference in numbers caught up and downwind of that trap are evidence that $P$. ariasi responds to the light of a CDC trap at distances $<2 \mathrm{~m}$ (the distance between the LS traps). By comparison, the range of attraction of a CDC trap to mosquitoes in West Africa was judged to be $<5 \mathrm{~m}$ (Odetoyinbo, 1969).

It is concluded that the use of CDC traps to recapture marked specimens of $P$. ariasi would not increase the distance of dispersal of the sandfly. The findings also show that a large aerial population of $P$. ariasi is in constant, active movement whenever the weather is suitable. On still warm nights, a CDC light trap in a good position will catch many non-teneral $P$. ariasi night after night. Since the distance of the attraction of the light appears to be less than $2 \mathrm{~m}$, the flies are not being drawn from far away; the catch is of mobile flies passing close to the trap.

Acknowledgements. This work was supported by the M.R.C., London, and WHO, Geneva. We gratefully acknowledge the technical assistance of Mr. L. Righton and Mr. T. Killick-Kendrick.

\section{REFERENCES}

Killick-Kendrick R., Rioux J.-A. : The Cévennes focus of leishmaniasis in southern France and the biology of the vector, Phlebotomus ariasi. In : Parasitological Topics (ed. E. U. Cancing) Society of Protozoologists Special Publication No I, I98I, I 36-I 45.

Killick-Kendrick R., Rioux J.-A., Bailly M., Guy M. W., Wilkes T. J., Guy F. M., DavidSon I., Knechtli R., Ward R. D., Guilvard E., Perieres J., Dubois H. : Ecology of leishmaniasis in the south of France. 20. Dispersal of Phlebotomus ariasi Tonnoir, I92 I as a factor in the spread of visceral leishmaniasis in the Cévennes. Ann. Parasitol. Hum. Comp. I 984 , s9, $555^{-572}$. 
Odetoyinbo J. A. : Preliminary investigation on the use of a light-trap for sampling malaria vectors in the Gambia. Bull. Wld Hlth Org., I969, 40, 547-560.

Rioux J.-A., Golvan Y. J., Croset H., Tour S., Houin R., Abonnenc E., Petitdidier M., VollhardT Y., Dedet J.-P., Albaret J. L., LANotTe G., Quillici M. : Epidémiologie des Leishmanioses dans le sud de la France. Monographie INSERM, 1969, no $37,223 \mathrm{p}$.

Rioux J.-A., Killick-Kendrick R., Leaney A. J., Turner D. P., Bailly M., Young C. J. : Ecologie des leishmanioses dans le sud de la France. I2. Dispersion horizontale de Phletomus ariasi Tonnoir, 1921. Expériences préliminaires. Ann. Parasitol. Hum. Comp., 1979, ${ }^{4}, 673-682$.

SnOw W. F. : The vertical distribution of flying mosquitoes (Diptera, Culicidae) in West African savanna. Bull. Ent. Res., 1975, 6\%, 269-277. 